Please do not remove this page

RMIT

UNIVERSITY

\title{
Low cost interdigital BST varactors for tunable microwave applications
}

Fardin, Ernest; Holland, Anthony; Ghorbani, Kamran

https://researchrepository.rmit.edu.au/esploro/outputs/9921861833501341/filesAndLinks?institution=61RMIT_INST\&index=null

Fardin, E., Holland, A., \& Ghorbani, K. (2005). Low cost interdigital BST varactors for tunable microwave applications. TENCON 2005 - IEEE Region 10 Conference, 1-4.

https://doi.org/10.1109/TENCON.2005.300884

Published Version: https://doi.org/10.1109/TENCON.2005.300884

Repository homepage: https://researchrepository.rmit.edu.au

(c) 2005 IEEE. Personal use of this material is permitted. However, permission to reprint/republish this material for advertising or promotional purposes or for creating new collective works for resale or redistribution to servers or lists, or to reuse any copyrighted component of this work in other works must be obtained from the IEEE.

Downloaded On 2023/04/26 22:31:38 +1000 


\title{
Low Cost Interdigital BST Varactors for Tunable Microwave Applications
}

\author{
Ernest A. Fardin, Kamran Ghorbani and Anthony S. Holland \\ School of Electrical and Computer Engineering \\ RMIT University \\ GPO Box 2476V, Melbourne, 3001, Australia \\ Email: efardin@ieee.org \\ Telephone: +61399253250 \\ Fax: +61 399252007
}

\begin{abstract}
In this paper, a simple and inexpensive technique for the fabrication of barium strontium titanate (BST) varactors is presented. BST films were deposited using RF magnetron sputtering on platinum coated silicon substrates. The advantages of silicon include low cost and ease of integration with existing fabrication processes. The microstructural properties of the BST layer were examined with scanning electron microscopy (SEM), $\mathrm{x}$-ray diffraction (XRD) and x-ray photoelectron spectroscopy (XPS) techniques. Gold top layer electrodes were deposited using DC sputtering and patterned with a conventional photolithographic process. The $S$-parameters of the varactor were measured from $40 \mathrm{MHz}$ to $20 \mathrm{GHz}$ on a vector network analyser. From this data, the capacitance, tunability and Q-factor of the device were extracted. The BST-based varactors show potential for integration into electronically tunable microwave circuits.
\end{abstract}

\section{INTRODUCTION}

There has been considerable research into the properties of $\mathrm{Ba}_{x} \mathrm{Sr}_{1-x} \mathrm{TiO}_{3}$ (BST) thin films in recent years. Potential applications of BST include high density dynamic random access memory (DRAM) [1], ferroelectric random access memory (FERAM) [2] and tunable microwave components [3]. The high, field dependent permittivity and low loss tangent of BST make it attractive as a dielectric material for electronically controlled microwave devices such as filters, phase shifters and matching networks [4]. Strong growth in RF-based applications over the past decade or so suggests a large potential market for these devices.

In order for BST-based microwave components to become commercially successful, it is important to minimise fabrication costs. Expensive, single-crystal substrates such as sapphire [5], $\mathrm{MgO}$ and $\mathrm{LaAlO}_{3}$ [6] have often been used as substrates for the deposition of BST thin films. These substrates have low microwave losses, and provide a good lattice match to BST. Many efforts have also been made to fabricate BST films on Pt/Si substrates [7], [3]. However, there are outstanding problems with the Pt bottom layer, which tends to form hillocks or cracks at the high temperatures used for BST deposition. In this paper, RF magnetron sputtering was used to deposit $\mathrm{Ba}_{0.5} \mathrm{Sr}_{0.5} \mathrm{TiO}_{3}$ films on low-cost platinised $\mathrm{Si}$ substrates. Tunable BST-based devices were produced, however a problem with cracking in the Pt layer was encountered and is the subject of ongoing work. The process that has

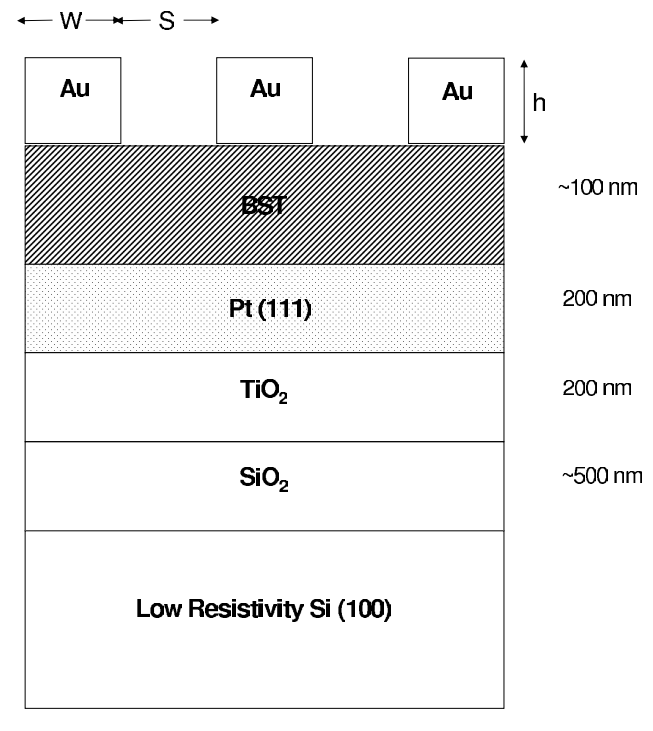

Fig. 1. BST thin film varactor cross section.

been developed could easily be transferred to high-resistivity $\mathrm{Si}$, since most microwave circuit applications require low-loss transmission lines for the connection of individual devices.

\section{INTERDIGITAL VARACTOR FABRICATION}

Low resistivity $20 \Omega \cdot \mathrm{cm}, 0.5 \mathrm{~mm}$ thick $\mathrm{Si}(100)$ wafers were used as the substrate material. A $500 \mathrm{~nm}$ film of $\mathrm{SiO}_{2}$ was deposited using RF magnetron sputtering at a working pressure of 10 mTorr and a substrate temperature of $120{ }^{\circ} \mathrm{C}$. The oxide layer serves as a diffusion barrier and inhibits silicide formation [8]. A Balzers BAK600 e-beam evaporation system was used to deposit 200nm layers of $\mathrm{TiO}_{2}$ and Pt successively. The $\mathrm{TiO}_{2}$ layer promotes adhesion of the $\mathrm{Pt}$ ground plane to the substrate. Because there was no radiation shield on the available e-beam evaporation system, the $\mathrm{TiO}_{2}$ and Pt layers were deposited at room temperature to prevent damage to the cryopump.

The BST layer was deposited at high temperature to promote the formation of a polycrystalline film. A resistive heater was used to heat the substrate to $625^{\circ} \mathrm{C}$ during BST deposition. 


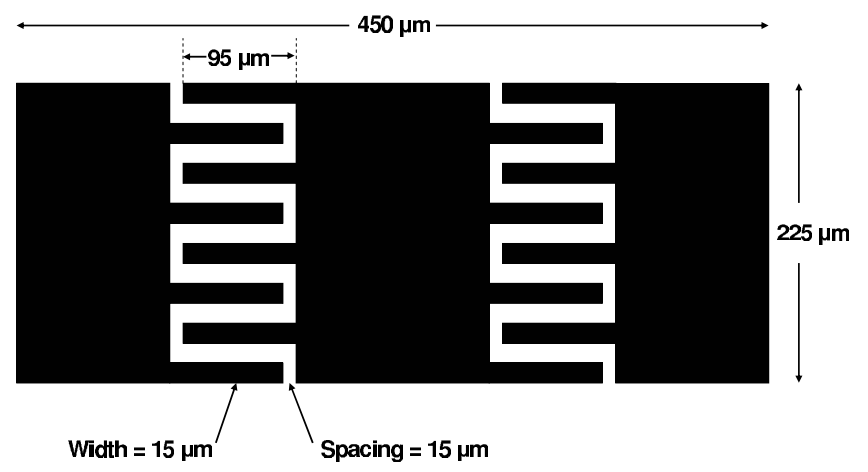

Fig. 2. Top electrode layout for ground-signal-ground wafer probing.

The films were on-axis magnetron sputtered from a $100 \mathrm{~mm}$ diameter target supplied by Williams Advanced Materials. The base pressure was $1 \times 10^{-5}$ Torr and the working pressure was 5 mTorr and 20 mTorr in a $\mathrm{Ar} / \mathrm{O}_{2}$ 9:1 atmosphere for different samples. A target to substrate distance of $60 \mathrm{~mm}$ was set for all depositions. No post-deposition anneal was performed. Finally, a thin layer of gold was DC sputtered on top of the BST film. A cross section of the layers comprising the device is shown in Fig. 1.

Interdigital top electrodes were patterned in the gold film using AZ5206E photoresist and a cyanide wet etch. In order that the high frequency properties of the film could be measured on a wafer probe station, the spacing of the contact pads had to match the wafer probes. PicoProbe $40 \mathrm{~A}$ probes with a spacing of $200 \mu \mathrm{m}$ were available. Because of the groundsignal-ground (GSG) configuration of the probes, each device consists of two sets of interdigital electrodes. The DC bias is applied to the central contact pad, and the outer pads serve as ground contacts. Many different interdigital devices were patterned on the BST sample, in order to realise a range of capacitances. The number of finger pairs per device ranged from 4 to 6 , the finger length from 50 to $100 \mu \mathrm{m}$, and the finger spacing ranged from 5 to $15 \mu \mathrm{m}$. The layout of an example device is shown in Fig. 2.

\section{RESULTS AND DISCUSSION}

In order to characterise the fabrication process, materials measurements were made following the completion of each major step in the procedure. X-ray diffraction (XRD) analysis of the Pt film confirmed a highly (111) oriented film, as reported by other groups [9], [10]. The thickness of the BST film was measured on an Tencor Alpha Step 200 profilometer. An average thickness of $107.5 \mathrm{~nm}$ was measured, with $\pm 10 \%$ variation across the sample. SEM analysis was used to determine the grain size in the BST film. The grain size is in the order of 50-100 $\mathrm{nm}$. Small cracks in the film, around $100 \mathrm{~nm}$ wide, are also evident in the micrograph. These can be attributed to the different thermal coefficients of the $\mathrm{Si}$ and $\mathrm{Pt}$ layers. The thermal coefficients of the Pt film and Si substrate are $8.8 \times 10^{-6}{ }^{\circ} \mathrm{C}^{-1}$ and $2.618 \times 10^{-6}{ }^{\circ} \mathrm{C}^{-1}$, respectively, at room temperature $[8]$.

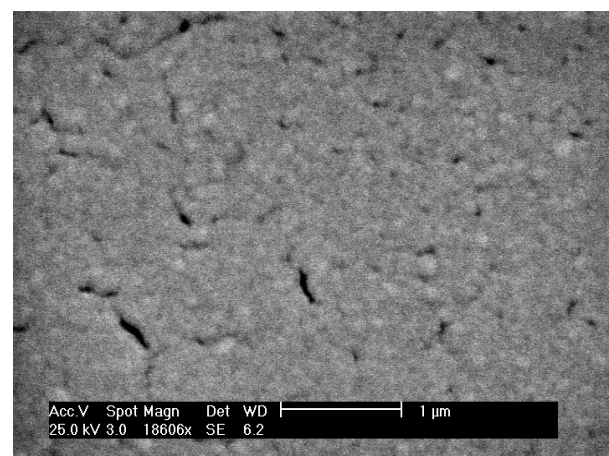

Fig. 3. SEM Micrograph of 5 mTorr RF magnetron sputtered BST film.

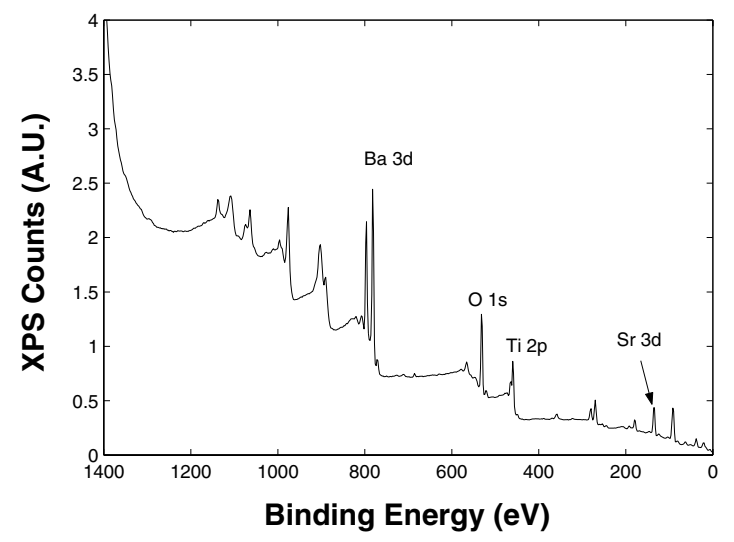

Fig. 4. XPS survey of 5 mTorr BST film after 5 minute surface sputter.

The composition of a BST film sputtered at 5 mTorr was studied using a MicroLab 310-F instrument for x-ray photoelectron spectroscopy (XPS) analysis. Measurements were made with non-monochromated $\mathrm{Al} \mathrm{K} \alpha$ radiation. Aside from the standard carbon signature inherent to XPS measurements, there was no significant trace of contaminants in the film. The carbon peak at $284.5 \mathrm{eV}$ is useful in compensating for sample charging during the XPS analysis. Using a calibration standard of BST powder from the sputtering target, it should be possible to determine an accurate elemental composition of the BST film. However, this was not available when the XPS measurement was performed; consequently, there is some uncertainty in the composition analysis. The XPS survey in Fig. 4 was taken after a 5 min sputter to remove the surface layer of the BST film containing the carbon signature. Composition results from the survey are given in Table I. The results suggest that the film is oxygen deficient, which may be due to the low $\mathrm{Ar} / \mathrm{O}_{2}$ atmosphere (5 mTorr) used for the deposition of the film. It has been reported elsewhere that oxygen vacancies contribute to dielectric loss in BST films [11]. Efforts are now underway to characterise the composition of the BST film as a function of the sputtering gas pressure.

X-ray diffraction was used to study the crystal structure of a BST film sputtered at 5 mTorr. The results, shown in Fig. 5, were obtained using $\mathrm{Cu} \mathrm{K} \alpha$ radiation with a detector slit width 
TABLE I

COMPOSITION RESULTS

\begin{tabular}{ccc}
\hline \hline Element & Ideal At. \% & XPS Meas. At. \% \\
\hline $\mathrm{Ba}$ & 10 & 13.8 \\
$\mathrm{Sr}$ & 10 & 11.6 \\
$\mathrm{Ti}$ & 20 & 20.4 \\
$\mathrm{O}$ & 60 & 54.2 \\
\hline \hline
\end{tabular}

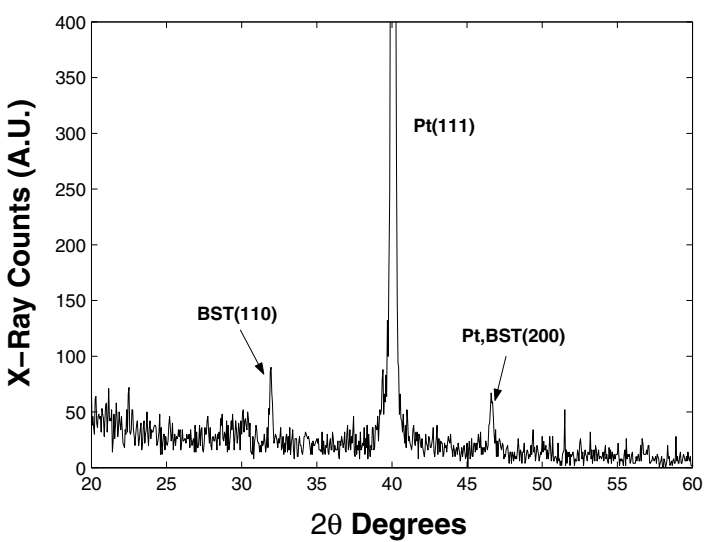

Fig. 5. XRD pattern of 5 mTorr magnetron sputtered film showing (110) BST orientation.

of $0.5 \mathrm{~mm}$ and a slit height of $2 \mathrm{~mm}$. The BST film is weakly oriented, with a (110) peak at $31.95^{\circ}$. This peak suggests a lattice parameter of $3.96 \AA$, 3\% larger than the bulk BST value of $3.9471 \AA[12]$.

Using an Anritsu 37369A vector network analyser (VNA), the two-port $\mathrm{S}$ parameters of the interdigital structures were measured from $40 \mathrm{MHz}$ to $20 \mathrm{GHz}$. This measurement was performed on a BST film sputtered at 20 mTorr. A calibration wafer supplied with the $200 \mu \mathrm{m}$ GSG probes was used to calibrate to the reference plane of the probe tips. For extraction of the dielectric parameters, the device with dimensions given in Fig. 2 was measured. Figure 6 shows the S-parameters of this device, at $0 \mathrm{~V}$ and $10 \mathrm{~V}$ bias. The change in $S_{21}$ with bias voltage demonstrates the phase-shifting property of the varactor. The capacitance of the device is quite large, and the impedance is very close to the short circuit point on the Smith chart beyond $1 \mathrm{GHz}$. Therefore, the device is useful as a tunable circuit element only at frequencies below $1 \mathrm{GHz}$. For tunability at high microwave frequencies, smaller device dimensions would be required. The $10 \mathrm{~V}$ DC bias corresponds to a field of $6.7 \mathrm{kV} / \mathrm{cm}$. Destructive testing to establish the breakdown field of the dielectric was not attempted.

In order to extract the capacitance and loss tangent of the device, the measured S-parameters were imported into Agilent Advanced Design System (ADS) 2004A. A simple parallel RC circuit was used to model the varactor over the frequency range of $40 \mathrm{MHz}$ to $2 \mathrm{GHz}$. Restricting the frequency range should ensure that the electrically small assumption implied with the lumped element equivalent circuit is valid. An optimisation

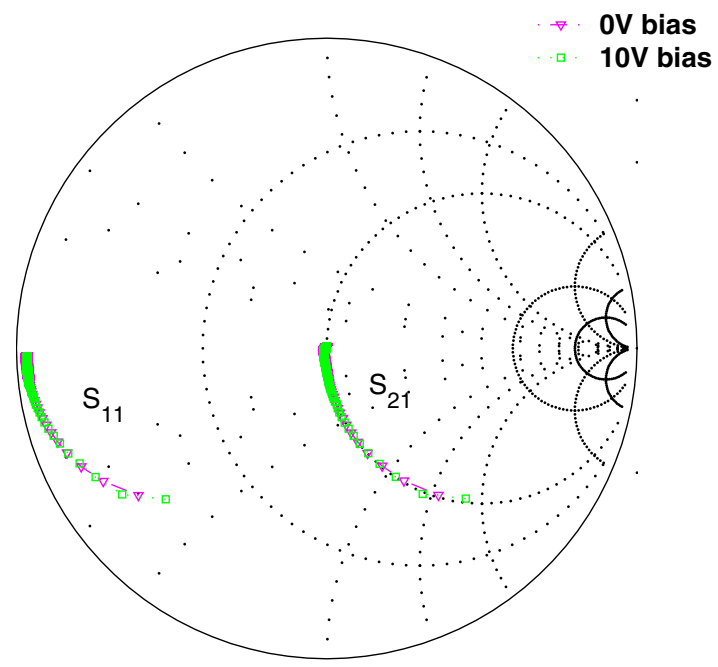

Fig. 6. Plot of device S-parameters from $40 \mathrm{MHz}$ to $20 \mathrm{GHz}$ at $0 \mathrm{~V}$ and $10 \mathrm{~V}$ bias.

TABLE II

Equivalent Circuit Model Parameters

\begin{tabular}{cccc}
\hline \hline DC Bias & $\mathrm{C}[p F]$ & $\mathrm{R}[\Omega]$ & $\mathrm{Q}$ at $40 \mathrm{MHz}$ \\
\hline $0 \mathrm{~V}$ & 198.8 & 0.72 & 27.8 \\
$10 \mathrm{~V}$ & 156.6 & 0.73 & 35.0 \\
\hline \hline
\end{tabular}

procedure, with equivalent circuit $\mathrm{R}$ and $\mathrm{C}$ as variables, was used to minimise the difference between the simulated and measured S-parameters. Once the equivalent $\mathrm{R}$ and $\mathrm{C}$ are known, the device $\mathrm{Q}$ can be calculated using $Q=1 / \omega R C$. The results of the extraction process are summarised in Table II.

These results indicate that the Pt groundplane leads to a much higher capacitance than devices which do not have a Pt bottom layer [6]. These earlier devices were of a similar size, with the BST layer deposited directly on to a single-crystal $\mathrm{LaAlO}_{3}$ substrate. At $0 \mathrm{~V}$ bias, these devices had a capacitance of $\sim 4 \mathrm{pF}$ at $10 \mathrm{GHz}$. Therefore, a metal groundplane may be useful as a means for reducing the dimensions of BST-based devices.

The relative permittivity $\epsilon_{r}$ of the dielectric was determined using a full wave electromagnetic simulation in Ansoft HFSS. To simplify the EM simulation, only half of the device, or one set of interdigital electrodes, was simulated. From the results in Table II, the maximum and minimum capacitances of this structure should be $99.4 \mathrm{pF}$ and $78.3 \mathrm{pF}$, respectively. Layer thicknesses measured during the fabrication process were used in the EM model. Sweeping the $\epsilon_{r}$ of the BST dielectric layer from 75 to 120 in the simulation, the capacitance extracted from the HFSS model varied from $68.9 \mathrm{pF}$ to $107 \mathrm{pF}$. Fitting the measured data to this curve, the maximum and minimum $\epsilon_{r}$ were 110.3 and 88 , respectively. The dielectric tunability 
can be defined as

$$
\text { Tunability }=\frac{\epsilon_{r, \max }-\epsilon_{r, \min }}{\epsilon_{r, \max }} .
$$

The dielectric tunability, according to (1), is $\sim 20 \%$. By a similar method, the capacitance tunability is $\sim 21 \%$. This is at the lower end of the range of values reported in the literature [13], which range from 7 to $75 \%$. However, by reducing the device dimensions and increasing the bias field, it should be possible to produce devices with competitive performance well into the microwave frequency range.

\section{CONCLUSION}

A process for the fabrication of BST thin-film varactors has been developed and demonstrated. The device S-parameters have been measured from $40 \mathrm{MHz}$ to $20 \mathrm{GHz}$. From this data, the capacitance and tunability from $40 \mathrm{MHz}$ to $2 \mathrm{GHz}$ have been extracted, and the results were compared with those of other research groups. A problem with cracking in the Pt film has been identified, and further work is required to address the problem. Efforts are also underway to characterise the electrical properties of the BST film as a function of the sputtering gas pressure.

\section{ACKNOWLEDGMENT}

The authors would like to thank the CASS Foundation, for their support of the project. Thanks also to Johan Du Plessis for performing the XPS measurements, to Andrew Chris, for assistance with the XRD measurements, and to Arnan Mitchell and Kourosh Kalantar-Zadeh for their helpful suggestions and discussions.

\section{REFERENCES}

[1] D. E. Kotecki et al., "(Ba,Sr) $\mathrm{TiO}_{3}$ dielectrics for future stacked-capacitor dram," IBM J. Res. Develop., vol. 43, pp. 367-382, May 1999.
[2] J. Jones, P. Zurcher, P. Che, D. Tayolr, Y. Lii, B. Jiang, P. Maniar, and S. Gillespie, "Memory applications based on ferroelectric and highpermittivity dielectric thin films," Microelectronic Engineering, vol. 29, pp. 3-10, 1995.

[3] O. Auciello, S. Saha, D. Kaufman, S. Streiffer, W. Fan, B. Kabius, J. Im, and P. Baumann, "Science and technology of high dielectric constant thin films and materials integration for application to high frequency devices," Journal of Electroceramics, vol. 12, pp. 119-131, 2004.

[4] A. Tombak, J.-P. Maria, F. Ayguavives, A. Jin, G. Stauf, A. Kingon, and A. Mortazawi, "Voltage controlled rf filters employing thin-film bariumstrontium-titanate tunable capacitors," IEEE Trans. Microwave Theory Tech., vol. 51, pp. 462-467, 2003.

[5] Y.-K. Yoon, D. Kim, M. Allen, J. Kenney, and A. Hunt, "A reduced intermodulation tunable ferroelectric capacitor-architecture and demonstration," IEEE Trans. Microwave Theory Tech., vol. 51, pp. 2568-2576, 2003.

[6] S. Kirchoefer, J. Pond, A. Carter, W. Chand, K. Agarwal, J. Horwitz, and D. Chrisey, "Microwave properties of $\mathrm{Sr}_{0.5} \mathrm{Ba}_{0.5} \mathrm{TiO}_{3}$ thin-film interdigitated capacitors," Microwave Opt. Tech. Letters, vol. 18, pp. 168-171, 1998

[7] P. Padmini, T. Taylor, M. Lefevre, A. Nagra, R. York, and J. Speck, "Realization of high tunability barium strontium titanate thin films by rf magnetron sputtering," Appl. Phys. Lett., vol. 75, pp. 3186-3188, 1999.

[8] B. Acikel, "High performance barium strontium titanate varactor technology for low cost circuit applications," Ph.D. dissertation, Univ. of California, Santa Barbara, 2002.

[9] N. Cramer, T. S. Kalkur, E. Philofsky, and L. Kammerdiner, "An equivalent circuit model for $\mathrm{Ba}_{0.5} \mathrm{Sr}_{0.5} \mathrm{TiO}_{3}$-based capacitors," Integrated Ferroelect., vol. 58, pp. 1395-1402, 2003.

[10] Y.-A. Jeon, W.-C. Shin, T.-S. Seo, and S.-G. Yoon, "Improvement in tunability and dielectric loss of $\left(\mathrm{Ba}_{0.5} \mathrm{Sr}_{0.5}\right) \mathrm{TiO}_{3}$ capacitors using seed layers on $\mathrm{Pt} / \mathrm{Ti} / \mathrm{SiO}_{2} / \mathrm{Si}$ substrates," J. Mater. Res., vol. 17, pp. 28312836, 2002.

[11] V. Vorobiev, P. Rundqvist, K. Khamchane, and S. Gevorgian, "Microwave loss mechanisms in $\mathrm{Ba}_{0.25} \mathrm{Sr}_{0.75} \mathrm{TiO}_{3}$ thin film varactors," $J$. Appl. Phys., vol. 96, pp. 4642-4649, 2004.

[12] Powder Diffraction File, Joint Committee on Powder Diffraction Standards Std. 39-1395, 1999.

[13] S. Gevorgian and E. Kollberg, "Do we really need ferroelectrics in paraelectric phase only in electrically controlled microwave devices?" IEEE Trans. Microwave Theory Tech., vol. 49, pp. 2117-2124, 2001. 